Volume 147 - No.4, August 2016

\title{
Comparative Analysis of Shunt Active Filter with PI controller and ANN based Controller
}

\author{
Munazama Ali \\ Dept.ofEEE \\ FET, Manav Rachna \\ International University, \\ Faridabad, India
}

\author{
Amrinder Kaur \\ Dept.of EEE \\ FET, Manav Rachna \\ International University, \\ Faridabad, India
}

\author{
Abdul Hamid Bhat, $\mathrm{PhD}$ \\ Dept.of EE \\ National Institute of \\ Technology Srinagar, Jammu \\ \& Kashmir, India
}

\begin{abstract}
Improving power quality has been the major research topic in last few decades due to flooding of semiconductor and other non-linear devices. The power quality of any source is determined by some indexes defined by international bodies such as harmonics factor, telephonic interference level (TIF) etc. Use different harmonic compensation schemes we must be able to meet those index limits. Power filters are widely used in modern electrical distribution systems to eliminate harmonic associated with it. The most popular technique that has been used is Active Power Filter (APF); The APF needs an accurate control algorithm that provides robust performance under source and load unbalances thus, compensation of harmonics depends largely on the algorithm adopted.

In this work both PI and ANN controller are used in threephase shunt active power filter to compensate harmonics and reactive power produces by nonlinear loads to improve power quality is implemented for three-phase three wire systems. PI and ANN-based technique is implemented in shunt active power filters depending on the requirement of one of the controller, used to produce controlled pulses required for IGBT inverter. The MATLAB program has been developed to simulate system operation. Various simulation results are presented in steady state condition and performance of PI and ANN controllers is compared. Simulation result obtained shows that performance of ANN controller found is better than PI controller.
\end{abstract}

\section{Keywords}

Shunt Active Power Filter(SAPF), Power filter topology, Passive filters, Ann controller.

\section{INTRODUCTION}

In recent years power quality distortion becomes serious problem in electrical power systems due to increase of nonlinear loads drawing non sinusoidal currents. Due to continuous development in technology and electronic equipments number of non-linear loads are increased exponentially, due to this production of characteristics and non-characteristic harmonics occur in the power system.. These loads draw non-sinusoidal current from ac mains and degrade the system performance [1]. To mitigate the harmonics, many different solutions are proposed and used by researchers in literature such as line conditioners, passive filters, active filter, etc. Firstly, conventional passive filter are used for elimination of the harmonics; but these passive filter having some disadvantages; such as large in size, fixed harmonic compensation, weight and resonance occurrence. Most of the pollution issues are created due to the nonlinear characteristics and fast switching of PE. Approximately 10\% to $30 \%$ of today's energy is processed by $\mathrm{PE}$; the percentage is estimated to reach about $50 \%$ to $80 \%$ by the year 2020 , due mainly to the fast growth of PE capability. A race currently take place between increasing PE pollution and sensitivity, on the one hand, the new PE-based corrective devices having the ability to attenuate the issues created by PE. however, perturbation rate has never reached present levels.

Various topologies of active power filters has been developed so far $[4,5]$.The shunt active power filter based on current controlled voltage source type PWM converter has proved to be effective even when the load is highly non-linear[1]. Most of the active filters developed are connected in parallel with nonlinear loads based on sensing harmonics and reactive voltampere requirements of non-linear load and require complex control [6, 7].

Conventional PI controller is used for generation of reference current template. The PI controller requires precise linear mathematical models, which are difficult to obtain and fails to perform satisfactory operation under parameter variation, nonlinearity, load disturbance, etc. A design criterion are described for selection of power circuit components. Both the control schemed are compared and the performance of both the controllers is investigated [11].

\section{HARMONIC COMPENSATION SCHEME}

Due to wide range of semiconductors and other non-linear devices, power quality has come down in the source. The two types of harmonic which are:-

\subsection{Characteristic Harmonic}

These are always present in system even the system is purely ideal and balanced; these harmonics are governed by certain mathematical equations. Their magnitude decrease with increase in order of harmonics. Usually even harmonics are ignored because of their dying nature due to symmetry.

\subsection{Non-Characteristic Harmonic}

Harmonic of the order other than characteristic harmonics are termed as non-characteristic harmonic. These occur due to unbalance and distortion in $\mathrm{AC}$ voltages and unequal transformer leakage impedances. These are also called residual harmonics.

\section{POWER FILTER TOPOLOGY}

Depending on the particular application or electrical problem to be solved, active power filters can be implemented as shunt type, series type, or a combination of shunt and series active filters (shunt-series type). These filters can also be combined with passive filters to create hybrid power filters. The shuntconnected active power filter, with a self-controlled dc bus, has a topology similar to that of a static compensator 
(STATCOM) used for reactive power compensation in power transmission systems. Shunt active power filters compensate load current harmonics by injecting equal-but opposite harmonic compensating current.

The Series active filter is the filter that is connected in series with the utility through a matching transformer, so it is controlled to eliminate voltage harmonics and regulate the terminal voltage of the load or line

However, The universal active filter (Unified Power Flow Controller, UPFC) is the filter that combines a shunt and a series active filters. It is controlled for both voltage and current harmonics cancellation.

Hybrid power filters are a combination of active and passive filters. With this topology the passive filters have dynamic low impedance for current harmonics at the load side, increasing their bandwidth operation and improving their performance.

\subsection{Passive Filters}

Passive filters are used as harmonic improvement devices in the power distribution system their performances are not satisfactory due to following reasons:

- Passive filter must be designed in consideration of current provided by nonlinear load and Source impedance affects compensation characteristics of LC filters.

- When contents of harmonics in the AC line increases the loading will be increase.

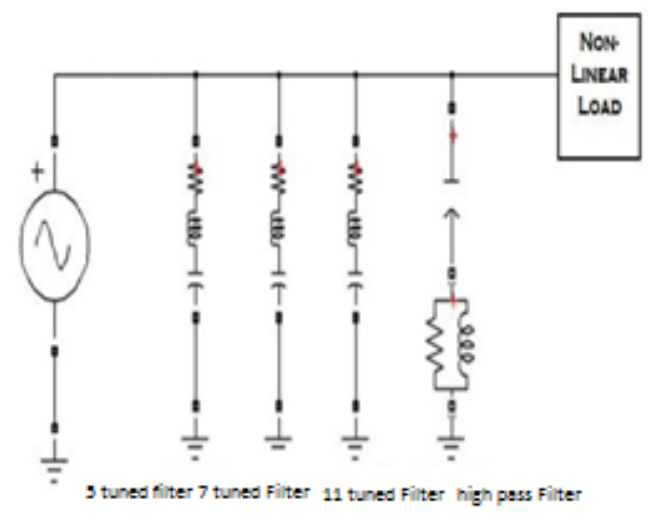

Figure 1: Basic diagram of passive Filter [1].

Having this much of disadvantages the harmonic control scheme becomes un-reliable and un-versatile.

\section{SHUNT ACTIVE POWER FILTER}

The active power filter was a recently developed piece of equipment for simultaneously delivering the compensating current to suppress the current harmonics on the ac side to make mains current sinusoidal .The active power filter is connected in parallel with nonlinear load. Active Power filters have wide application in modern electrical distribution system for eliminating the harmonics associated with it. Shunt active power filter (SAPF) is one of power filters which have better dynamic performance and it needs an accurate control algorithm that provides robust performance. The control methods are responsible for generating reference currents which are used to trigger the Voltage Source Inverters.
It has been used to:

- Eliminate current harmonics

- Balance and regulate terminal voltage of load/line.

- $\quad$ Reduce negative sequence voltage.

- Installed by electric utilities to compensate voltage harmonics and swamp out harmonic propagation caused by resonance with line impedances and passive shunt $\mathrm{E}$ compensator

\subsection{Basic Compensation Principle}

The active power filter is controlled to deliver the compensating current if from/to the load on the AC side and reactive power flow from/to the source there by making the source current in phase with source voltage.

Figure 2 shows basic compensation principle of the shunt active power filter. It is controlled to draw/ supply a compensating current ic from/to the utility, so that it cancels current harmonics on the AC side, and makes the source current in phase with the source voltage.

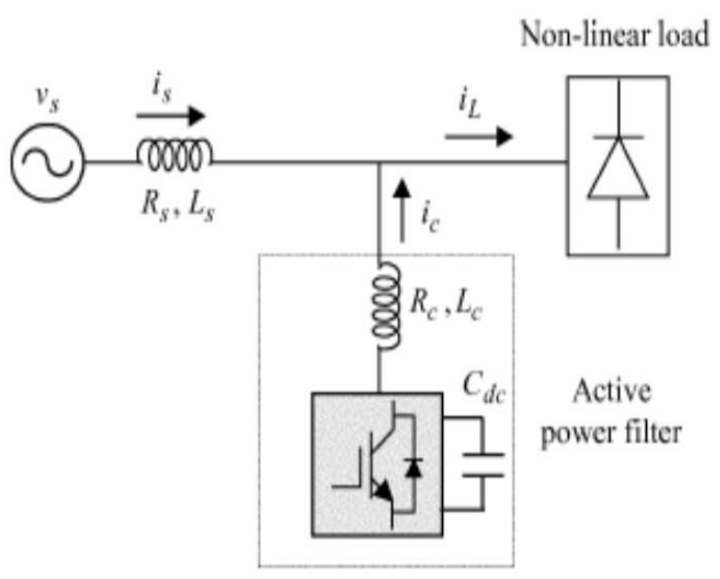

Figure 2: Shunt active power filters Basic compensation principle [4].

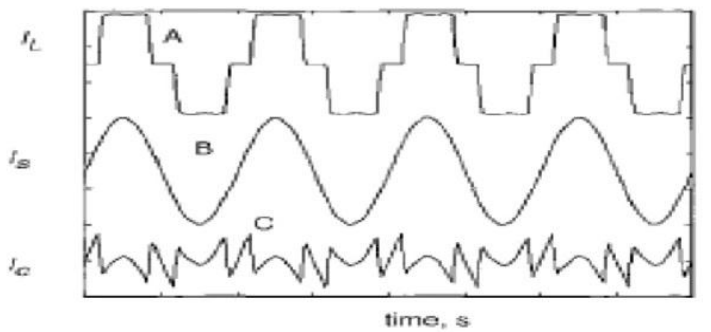

Figure 3: Shunt active power filter(SAPF)-Shapes of load, source and desired filter current wave forms [5].

Figure 3 above shows the different waveforms. Curve A represents load current waveform, curve B is desired load current and curve $\mathrm{C}$ shows the compensating current injected by active power filter contains all the harmonics to make mains current sinusoidal. 
Volume 147 - No.4, August 2016

\subsection{Estimation Of Reference Source Current}

From figure 2 the instantaneous current can be written as:

$i_{S(t)}=i_{L(t)}-i_{C(t)}$

Source voltage is given as:

$v_{s(t)}=\sin \omega t$

If a non-linear load has applied, then the load current will have a fundamental component and harmonic components which can be represented by

$$
\begin{aligned}
i_{L(t)} & =\sum_{n=1}^{\alpha} I n \sin \left(n \omega t+\phi_{n}\right) \\
& =I_{1} \sin \left(n \omega t+\phi_{1}\right)+\sum_{n=2}^{\alpha} \sin \left(n \omega t+\phi_{n}\right)
\end{aligned}
$$

The instantaneous load power can be given as:

$$
P_{L(t)}=V_{s(t)} * i_{l(t)}
$$

$V_{m} I_{1} \sin \omega t \omega \mathrm{t}^{*}+V_{m} I_{1} \sin \omega \mathrm{t}^{*} \cos \omega \mathrm{t}^{*} \sin \phi_{1}+V_{m} \sin \omega t * \sum_{n=2}^{\infty} \sin ($ $\left.\mathrm{n} \omega \mathrm{t}+\phi_{n}\right)$

$$
=P_{f(t)}+P_{r}(\mathrm{t})+P_{h}(\mathrm{t})
$$

From (2.2.4), the real (fundamental) power drawn by the load is:

$P_{f}(\mathrm{t})=V_{m} I_{1} \sin ^{2} \omega \mathrm{t} * \cos \phi_{1}=v_{s}(\mathrm{t}) * i_{s}(\mathrm{t})$

From (2.2.5), the source current supplied by the source, after compensation is:

$i_{s}(\mathrm{t})=P_{f}(\mathrm{t}) / v_{s}(\mathrm{t})=I_{1} \cos \phi_{1} \sin \omega \mathrm{t}=I_{m} \sin \omega \mathrm{t}$

Where $I_{s m}=I_{1} \cos \phi_{1}$

There are also some switching losses in the PWM converter, and hence the utility must supply a small overhead for the capacitor leakage and converter switching losses in addition to the real power of the load. The total peak current supplied by the source is therefore

$I_{s p}=I_{s m}+I_{s I}$

If the active filter provide total reactive and harmonic power, then is $(\mathrm{t})$ will be in phase with the utility voltage and purely sinusoidal. At this time, the active filter must provide following compensation current:

$I_{c}(t)=I_{l}(\mathrm{t})-I_{s}(\mathrm{t})$

Hence, for accurate and instantaneous compensation of reactive and harmonic power it is necessary to estimate, i.e. fundamental component of the load current as the reference current.

\subsection{Estimation of Reference Source Current}

The peak value of the reference current Isp can be estimated by controlling DC side capacitor voltage. Ideal compensation requires the mains current to be sinusoidal and in phase with the source voltage, irrespective of the load current nature. The desired source currents, after compensation, can be given as

$I_{s a} *=I_{s p} \sin \omega \mathrm{t}$

$I_{s b} *=I_{s p} \sin \omega \mathrm{t}\left(\omega \mathrm{t}-120^{\circ}\right)$

$I_{s c} *=I_{s p} \sin \left(\omega \mathrm{t}+120^{\circ}\right)$

Where $I_{s p}=\left(I_{1} \cos \phi_{1}+I_{s l}\right.$ the amplitude of the desired source current, while the phase angle can be obtained from the source voltage. hence, waveform and phases of source currents are known, and only the magnitudes of the source currents need to be determined. This peak value of the reference current has estimated by regulating DC side capacitor voltage of PWM converter. This capacitor voltage is compared with a reference value and the error is processed in a PI or ANN controller. The output of the PI or ANN controller has been considered as the amplitude of the desired source current, and the reference currents are estimated by multiplying this peak value with unit sine vectors in phase with the source voltages parameters:

- $\quad$ Selection of the filter inductor, Lc.

- Selection of the DC side capacitor, Cdc.

- Selection of the reference value of DC side capacitor voltage, Vdc,ref.

\section{ANN CONTROLLER SCHEME}

Recently, Artificial Neural Networks (ANN) have attracted much different applications, including the APF. The Active power filters has been shown to be very interesting alternative to compensate in power distribution systems. Shunt active power filter are more suitable to compensate current harmonic components and displacement power factor, while series topologies present better characteristics to the compensate voltage distortions. Hybrid topology significantly improved compensation characteristics of the simple passive filters, making active power filter available for the different high power applications, at relative lower cost. An additional PI controller is used to regulate the dc-link voltage. The adaptive controller can adapts for unbalancing and change the working conditions. Here integration of Ann based predictive and adaptive control techniques are used to generate gating pulses for voltage source inverter. The Artificial Neural Networks (ANNs) has been systematically applied to the electrical engineering. This method is considered to be a new tool to design SAPF control circuits. The ANN presents two principal characteristics .It's not necessary to establish specific input-output relationships but they are formulated through a learning process. Moreover, the parallel computing architecture increases the system speed and reliability. In this paper, a new SAPF control method based on ANNs has been presented. Load voltages and currents are sensed, the control blocks calculates the power circuit control signals from the reference compensation currents, and the power circuit injects the compensation current to power system.

\section{PERFORMANCE EVALUATION}

In this paper SAPF model is proposed, shown in figure below.

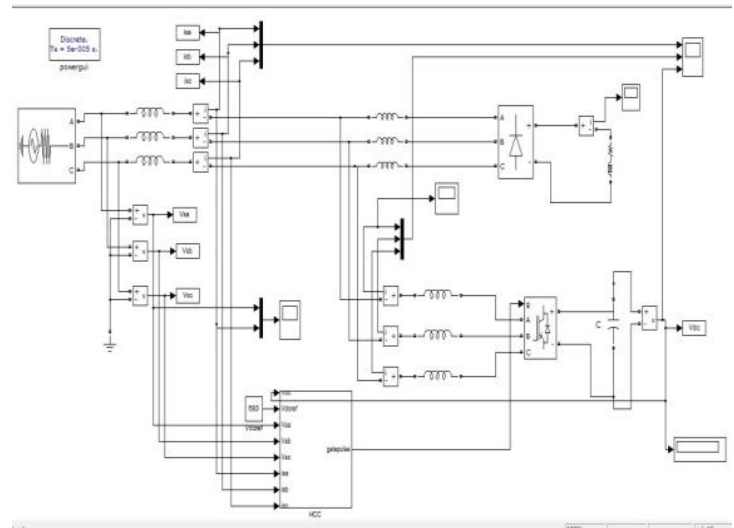

Figure 4: Simulation model of Shunt Active Power Filter(SAPF). 
The simulation is carried out with the three phase three wire system with non-linear load. Here the diode rectifier is used as non-linear load. The Figure 5 shows the three phase current waveform without any filter or the controller circuit. From this simulation, three phase source currents are taken as the output. THD value is high because we won't use any controller in this circuit. A program is developed to simulate both the ANN controller and PI logic based shunt active power filter in MATLAB. The complete active power filter system is composed mainly of the three-phase source, a nonlinear load, a voltage source PWM converter, and a ANN controller. All these components are modelled separately, integrated and then solved to simulate the system.

The SAPF is switched to the system at $0.2 \mathrm{sec}$. The responses before and after switching can be easily distinguished from the waveform and THD values given in the figures below.

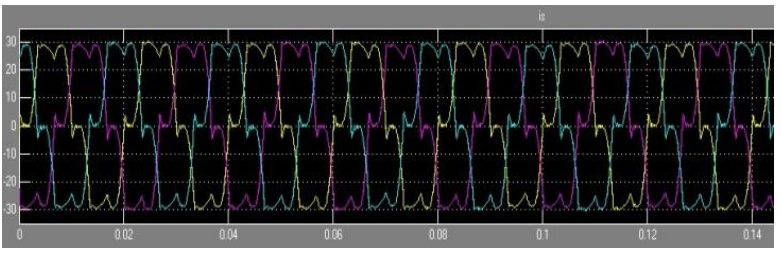

Figure 5: waveform of Three phase source currents without active filter.
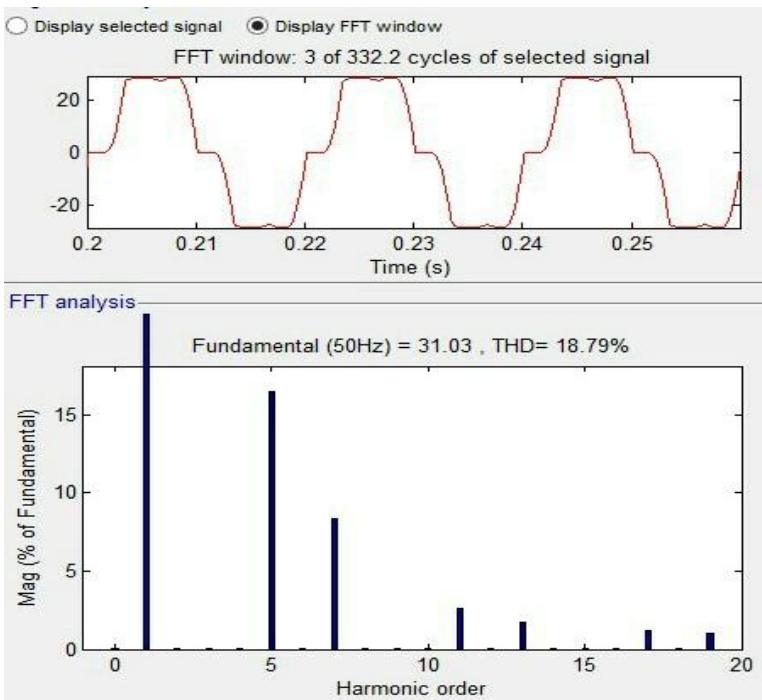

Figure 6: Harmonic spectrum without active filter.

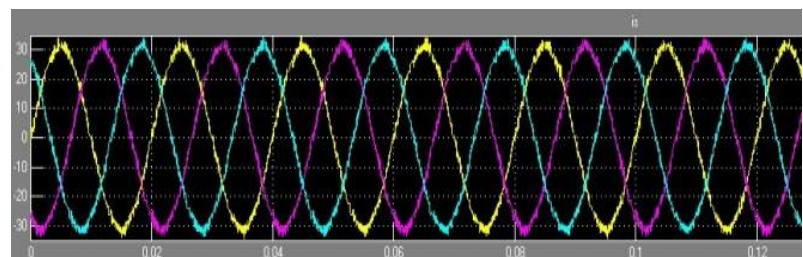

(a)

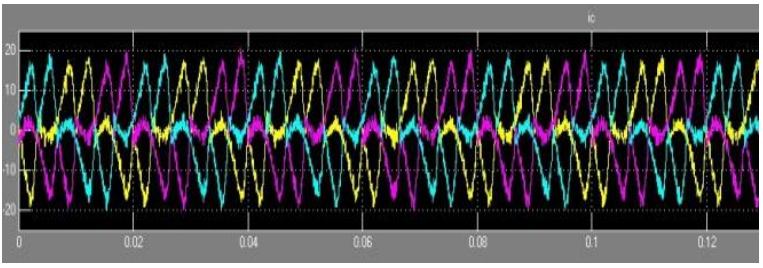

(b)

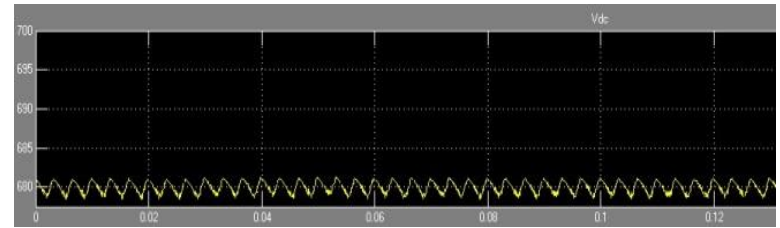

(c)

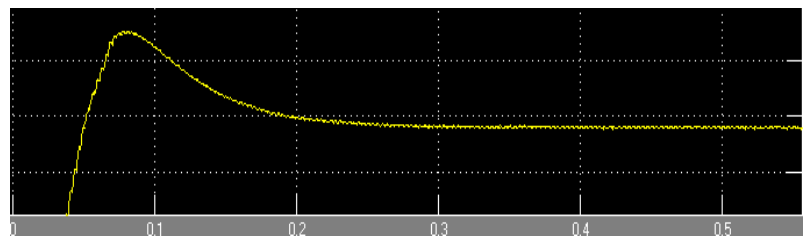

(d)

Figure 7: Three phase balanced (a) source current (b)SAPF Injected current (c) DC link voltage with PI Controller (d) $V_{d c}$ settling time with PI Controller.

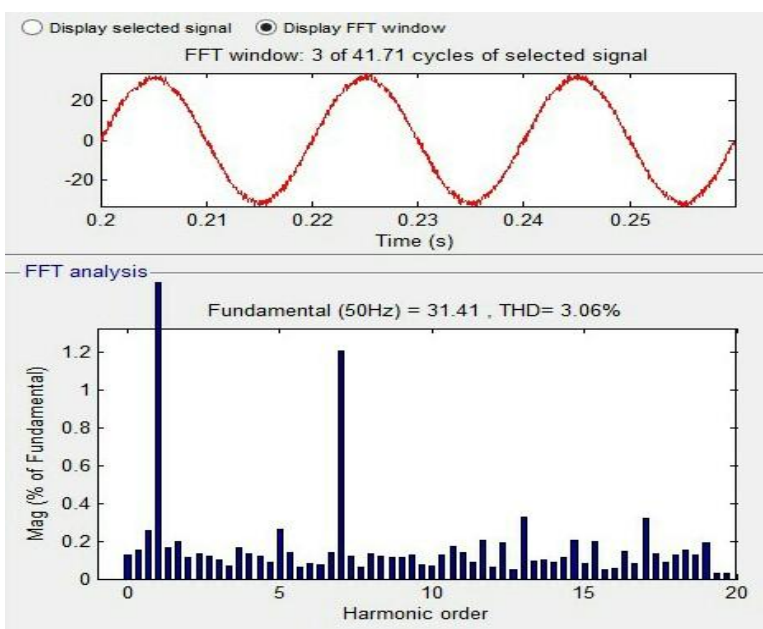

Figure 8: Total Harmonic distortion with PI Controller.

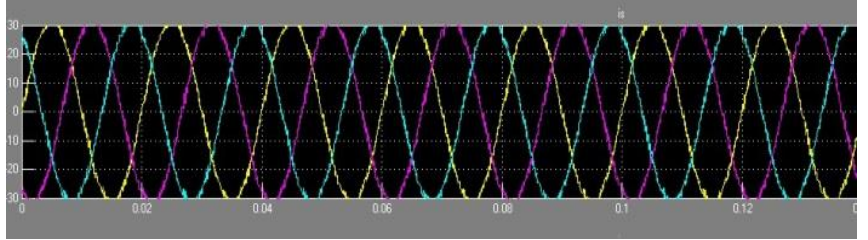

(a)

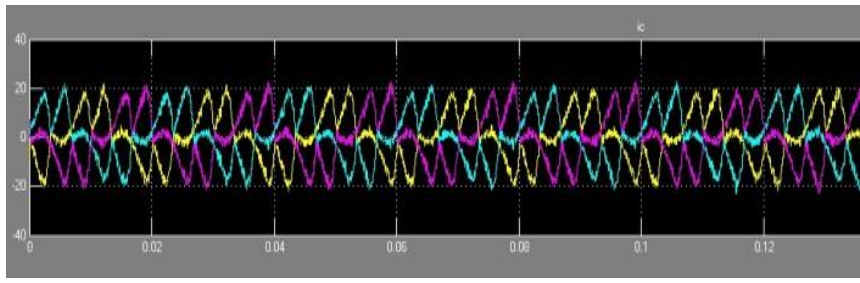

(b)

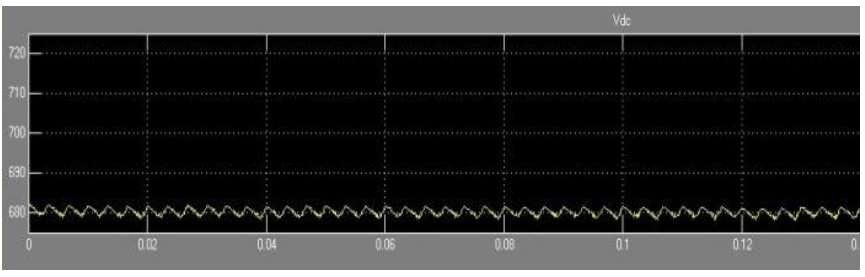

(c) 


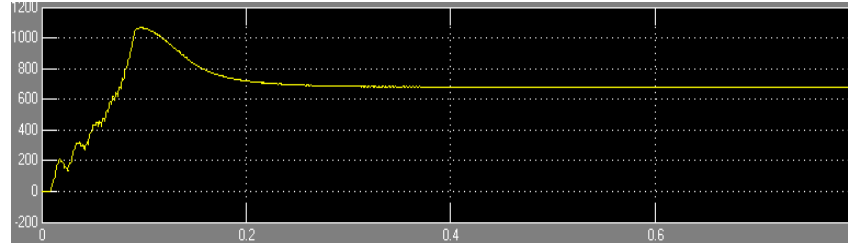

(d)

Figure 9: Three phase balanced (a)Source current (b)SAPF Injected current(c)DC link voltage with ANN Controller (d) $V_{d c}$ settling time with ANN Controller.

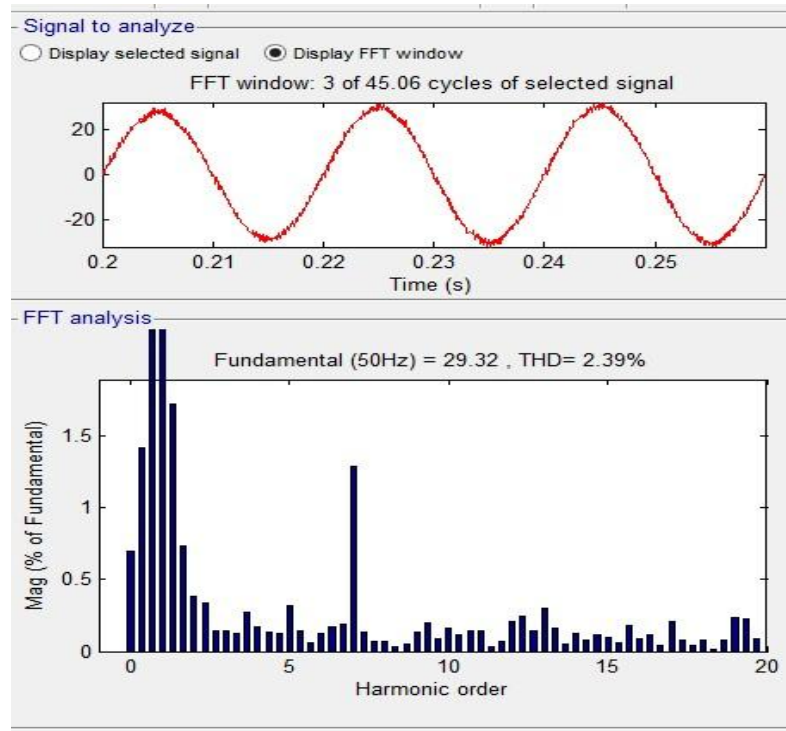

Figure 10: Total Harmonic distortion with ANN controller.

Table 1: THD With different controllers.

\begin{tabular}{|l|c|c|}
\hline \multicolumn{3}{|c|}{ THD With Different Controllers } \\
\hline $\begin{array}{l}\text { Without } \\
\text { SAPF }\end{array}$ & PI Controller & ANN Controller \\
\hline 18.79 & 3.06 & 2.39 \\
\hline
\end{tabular}

\section{CONCLUSION}

The Power quality management has been the main problem that the industries are facing today. This is mainly affected by generation of harmonics. The growing use of electronic equipment produces a large amount of the harmonics in the distribution systems because of non-sinusoidal currents consumed by non-linear loads. In this paper and we clearly calculate the Total Harmonic distribution(THD) with shunt active power filter and without shunt active power filter.

In the paper two controllers are developed and verified for the three phase three wire systems. Even though both the presented controllers are capable of compensating line current harmonics in 3 phase 3-wire systems, it can be seen that the ANN controller has a better dynamic performance than the conventional PI controller. Hysteresis current control is used for quick response for the generating gate pulses. It can also be seen that the DC voltage regulation system is a stable. The SAPF is observed to eliminate the harmonic and reactive components of load current resulting in sinusoidal and unity power-factor source currents. It is observed that the source current remains below the load current even during transient conditions. The SAPF enhances the system efficiency because the source need not process the harmonic and reactive power demanded by the load. Among many approaches for determining the SAPF reference compensation currents, one of the main streams is to maintain sinusoidal source currents supplying average real power to the load. With the use of sinusoidal source current strategy, it is proved that the SAPF can have better performance than other strategies.

\section{REFERENCES}

[1] W. Mackgrady, S. Santoso, Understanding power system harmonics, IEEE power Eng. Rev. 21(November (11)) (2001) 8-11.

[2] A novel and analytical model for design and implementation of active power filter' IEE proc-electr., power appl.,vol.148,no.4,july 2001.

[3] Nasser Mondale and Kamala Al-Haddad Modelling and Nonlinear Control of Shunt Active Power Filter in the Synchronous Reference Frame.2000 IEEE.

[4] H. Akagi, Y. Kanzawa, and A. Nabae (1984) Instantaneous reactive power compensators comprising switching devices without energy components. IEEE Trans. Ind. Appl., 20 (3), pp. 625-630.

[5] S. Jain, P. Agarwal, and H. O. Gupta, "Design simulation and experimental investigations on a shunt active power filter for harmonics and reactive power compensation," Electrical Power Components and Systems, vol. 32, no. 7, Jul. 2003, pp. 671-692.

[6] J.W. Dixon, J.J. Garcia \& L .Morgan, "Control system for three phase active power filter which simultaneously compensates power factor and unbalanced loads," IEEE Transactions on Industrial Electronics, vol.42, no.6, 1995, pp636-641.

[7] L. A. Morgan, J. W. Dixon \& R. R. Wallace, "A three phase active power filter operating with fixed switching frequency for reactive power and current harmonics compensation," IEEE Transactions on Industrial Electronics, vol.42, no.4, August 1995, pp 402-408.

[8] B. Singh, A. Chandra, and K. Al-Haddad, "Computeraided modelling and simulation of active power filters," Electrical Machines and Power Systems, vol. 27, 1999, pp. 1227-1241.

[9] B. Singh, V.Verma, and J. Solanki, "Neural networkbased selective compensation of current quality problems in distribution system," IEEE Trans. Ind. Electron., vol. 54, no. 1, pp. 53-60, Feb. 2007.

[10] Active power filter for reactive power compensation and Harmonic suppression by Hurng- Liahng job.

[11] B. Singh, A. Chandra, and K. Al-Haddad, "A review of active filters for power quality improvement," IEEE Transactions on Industrial Electronics, vol.46, no 5, Oct 1999, pp1-12.

[12] Bhim Singh, Kamal Al-Haddad "A review of Active Filters for Power Quality Improvement", IEEE Transactions on Industrial Electronics, vol. 46, no. 5, October 1999.

[13] Simulink-Model-Based and System-Based Design, Modelling, Simulation, Implementation version 5,The Mathn Works, July 2002. 
[14] Joao L afonso, H J Ribeiro Silva, Julio, S Martin, “Active Filter For Power Quality Improvement"2001 IEEE Porto Power tech, 10-13 set, 2001 Porto Portugal.

[15] IEEE Working Group on Non sinusoidal Situations: Effects on Meter Performance and Definitions of Power, "Practical definitions for powers in systems with non sinusoidal waveforms and unbalanced loads: a discussion," IEEE Trans. Power Delivery, vol. 11, no. 1, pp. 79-101, Jan. 1996.

[16] Yash Pal, A. Swarup, and Bhim Singh, "Applications of APF for Power Quality Improvement" IEEE Transactions On Power Systems conference, December, 2010.

[17] Boren Renlin, Richard G Hoft. Power electronics inverter with neural networks. IEEE Technology update series. 1997; 12(2).

[18] A. E. Emanuel, "Summary of IEE Standard1459:definition for the measurement of electric power quantities under sinusoidal, non sinusoidal, balanced, or unbalanced conditions," IEEE Trans. Ind. Appl., vol. 40, no. 3, pp. 869-876, May/Jun. 2004.

[19] Metin Kesler and Engin Ozdemi“'Synchronous Referen Frame-Based Control Method for SAPF Under
Unbalanced and Distorted Load Conditions", IEEE transactions on industrial electronics, VOL. 58, NO. 9, SEPTEMBER 2011.

[20] R Rajalakshmi, Dr V Rajasekaran, "Improvement ofEnergy Efficiency through power quality by compensation of harmonics with shunt active power filter"2011 International Conference advancements in electrical, electronics and control engineering IEEE.

[21] JR Vázquez, PatricioSalmeron, F Javieralcantra, JainePrieto. A new active power line conditioner for compensation in unbalanced /distorted electrical power system. 14th PSCC, Sevilla. 2002.

[22] Elsa Susan Daniel and G. Abirami "Selective Harmonic Elimination Using Shunt Hybrid Active Power Filters Operating At Different Switching Frequencies" International Journal of Innovative Research In Electrical \& Electronics, Instrumentation And Control Engineering Vol. 1, Issue 1, April 2013

[23] T.Mahalekshmi "Current Harmonic Compensation and Power Factor Improvement by Hybrid Shunt Active Power Filter" International Journal of Computer Applications (0975 - 8887) Volume 4 - No.3, July 2010. 